\title{
Complete and safe resection of challenging retroperitoneal tumors: anticipation of multi- organ and major vascular resection and use of adjunct procedures
}

William W Tseng ${ }^{1,3}$, Sam C Wang ${ }^{1}$, Charles M Eichler ${ }^{2}$, Robert S Warren ${ }^{1}$ and Eric K Nakakura ${ }^{1 *}$

\begin{abstract}
Background: Retroperitoneal tumors are often massive and can involve adjacent organs and/or vital structures, making them difficult to resect. Completeness of resection is within the surgeon's control and critical for long-term survival, particularly for malignant disease. Few studies directly address strategies for complete and safe resection of challenging retroperitoneal tumors.
\end{abstract}

Methods: Fifty-six patients representing 63 cases of primary or recurrent retroperitoneal tumor resection between 2004-2009 were identified and a retrospective chart review was performed. Rates of complete resection, use of adjunct procedures, and perioperative complications were recorded.

Results: In 95\% of cases, complete resection was achieved. Fifty-eight percent of these cases required en bloc multi-organ resection, and $8 \%$ required major vascular resection. Complete resection rates were higher for primary versus recurrent disease. Adjunct procedures (ureteral stents, femoral nerve monitoring, posterior laminotomy, etc.) were used in 54\% of cases. Major postoperative complications occurred in 16\% of cases, and one patient died (2\% mortality).

Conclusions: Complete resection of challenging retroperitoneal tumors is feasible and can be done safely with important pre- and intraoperative considerations in mind.

Keywords: Retroperitoneal Tumor, Multi-organ Resection, Adjunct Procedures

\section{Background}

Retroperitoneal tumors are relatively uncommon but can be very challenging to manage, even for the experienced surgeon. For malignant disease, which accounts for most retroperitoneal tumors [1,2], prognosis depends on tumor grade and histologic subtype, completeness of resection, and presence of distant metastases [3-6]. These factors are for the most part, dependent on tumor biology; however, the ability to completely resect a retroperitoneal tumor is within the control of the surgeon and has tremendous impact on long-term survival $[3,4,6]$. With greater experience and improved operative

\footnotetext{
* Correspondence: eric.nakakura@ucsfmedctr.org

'Divisions of Surgical Oncology, University of California at San Francisco

(UCSF), 505 Parnassus Avenue, San Francisco, CA 94143 USA

Full list of author information is available at the end of the article
}

technique, many centers have recently reported complete resection rates over $90 \%$ and, consequently, better clinical outcome [7-9]. However, as retroperitoneal tumors can be enormous and often involve multiple adjacent organs and vital structures, successful complete resection must also be carefully balanced with patient safety.

Few studies directly address strategies for complete and safe resection of challenging retroperitoneal tumors. In this retrospective review, we describe important preand intraoperative considerations based on our recent experience with challenging retroperitoneal tumors in patients at a tertiary referral center.

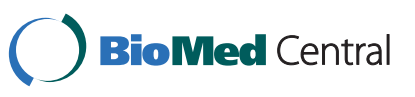

() 2011 Tseng et al; licensee BioMed Central Ltd. This is an Open Access article distributed under the terms of the Creative Commons Attribution License (http://creativecommons.org/licenses/by/2.0), which permits unrestricted use, distribution, and reproduction in any medium, provided the original work is properly cited. 


\section{Materials and methods}

After obtaining institutional review board approval, we identified 56 adult patients with primary or recurrent retroperitoneal tumors who underwent a total of 63 resections at the University of California San Francisco Medical Center between 2004 and 2009. Their charts were retrospectively reviewed to determine rates of complete resection and perioperative complications. Specific attention was also given to adjunct procedures used to improve resectability and minimize complications. Data was also collected regarding patient demographics (age, sex), tumor characteristics (size, pathology, grade), operative details (blood loss, operative time) and hospital course (length of stay).

Before surgery, all patients underwent a thorough evaluation of co-morbid conditions, and cardiac and pulmonary function were optimized. Contrast-enhanced computed tomographic scanning or magnetic resonance imaging was done to evaluate the local extent of tumor and rule out presence of metastatic disease before resection. On the basis of their preoperative imaging results, patients were further evaluated by consulting services as needed (e.g., urology for ureteral stent placement and/or nephrectomy; vascular surgery for major vessel resection, graft selection/sizing and reconstruction; neurosurgery for potential spinal nerve root involvement). Preoperative tissue diagnosis was available in some patients but was not required before surgery if the result would not have affected patient care.

\section{Results}

Median age for all patients was 52 years (range 22-77) with an even distribution of male and female patients. Out of 63 retroperitoneal tumor resections, 35 (56\%) were performed for primary disease, 28 (44\%) for recurrence. Median operative time was 316 minutes (range 149-759). Median estimated blood loss was 500 cc (range 50-25,000).

Complete resection, as defined by macroscopically negative margins (R0-R1), was achieved in 95\% of all operations performed (Table 1). In three patients, complete resection was not possible because of extensive peritoneal sarcomatosis at laparotomy $(n=2)$ and significant intraoperative bleeding ( $\mathrm{n}=1$, discussed below). Complete resection was feasible, but achieved slightly less often in resections performed for recurrent tumors (93\%) versus primary tumors (97\%, Table 1). Tumor involvement of adjacent organs necessitated concomitant en bloc resection to achieve macroscopically negative margins in $58 \%$ of all cases (Table 1 ). The kidney, colon, and pancreas were the most frequently involved and resected organs. In $8 \%$ of cases, major vascular (e.g. inferior vena cava, iliac vessel) resection was required.
Table 1 Operative Details

\begin{tabular}{|c|c|c|c|}
\hline \multirow{3}{*}{$\begin{array}{l}\text { Complete Resection } \\
\text { (out of } n=63 \text { cases: } 35 \text { primary, } 28 \\
\text { recurrent) }\end{array}$} & \multicolumn{3}{|c|}{ No. of cases (\%) } \\
\hline & Total & Primary & Recurrent \\
\hline & $\begin{array}{c}60 \\
(95)\end{array}$ & $34(97)$ & $26(93)$ \\
\hline Multi-organ Resection & $\begin{array}{c}35 \\
(58)\end{array}$ & $21(62)$ & $14(54)$ \\
\hline \multicolumn{4}{|l|}{$\begin{array}{l}\text { (out of } n=60 \text { cases with complete } \\
\text { resection) }\end{array}$} \\
\hline Kidney & $\begin{array}{c}18 \\
(30)\end{array}$ & 10 & 8 \\
\hline Colon & $\begin{array}{c}10 \\
(17)\end{array}$ & 3 & 7 \\
\hline Pancreas & $4(7)$ & 3 & 1 \\
\hline Small bowel & $3(5)$ & 1 & 2 \\
\hline Adrenal & $3(5)$ & 3 & 0 \\
\hline Bladder & $2(3)$ & 2 & 0 \\
\hline Liver & $1(2)$ & 1 & 0 \\
\hline Spleen & $1(2)$ & 1 & 0 \\
\hline Diaphragm & $1(2)$ & 1 & 0 \\
\hline Iliac wing & $1(2)$ & 0 & 1 \\
\hline Major Vascular resection & $5(8)$ & $3(9)$ & $2(8)$ \\
\hline \multicolumn{4}{|l|}{$\begin{array}{l}\text { (out of } n=60 \text { cases with complete } \\
\text { resection) }\end{array}$} \\
\hline IVC & $4(7)$ & 3 & 1 \\
\hline Iliac artery, vein & $1(2)$ & 0 & 1 \\
\hline \multicolumn{4}{|l|}{ Adjunct Procedures } \\
\hline \multicolumn{4}{|l|}{ (out of $n=63$ cases) } \\
\hline Posterior laminotomy & $3(5)$ & 2 & 1 \\
\hline Angioembolization & $2(3)$ & 2 & 0 \\
\hline Ureteral stent & $\begin{array}{c}22 \\
(35)\end{array}$ & 14 & 8 \\
\hline Femoral nerve monitoring & $7(11)$ & 3 & 4 \\
\hline
\end{tabular}

In each case, anatomic vascular reconstruction was done immediately after resection by using synthetic tube grafts (for inferior vena cava) or cryopreserved human vein (for iliac vessels) (Figure 1). Among patients who had complete resection, the rates of multi-organ or major vascular resection were higher in those with primary disease $(71 \% ; n=24 / 34)$ than in those with recurrent disease $(62 \% ; n=16 / 26)$.

Several pre-operative and intraoperative adjunct procedures were used to facilitate safe and complete resection in $54 \%$ of cases (Table 1 ). The decision to use any of these procedures was based on careful review of preoperative imaging studies that raised concern for tumor involvement of critical structures. For example, in three patients, a posterior laminotomy was done by neurosurgeons because preoperative imaging suggested spinal nerve root involvement. In two patients whose CT scans suggested high tumor vascularity, preoperative angioembolization was done by interventional radiologists to limit intraoperative blood loss. To help identify and 


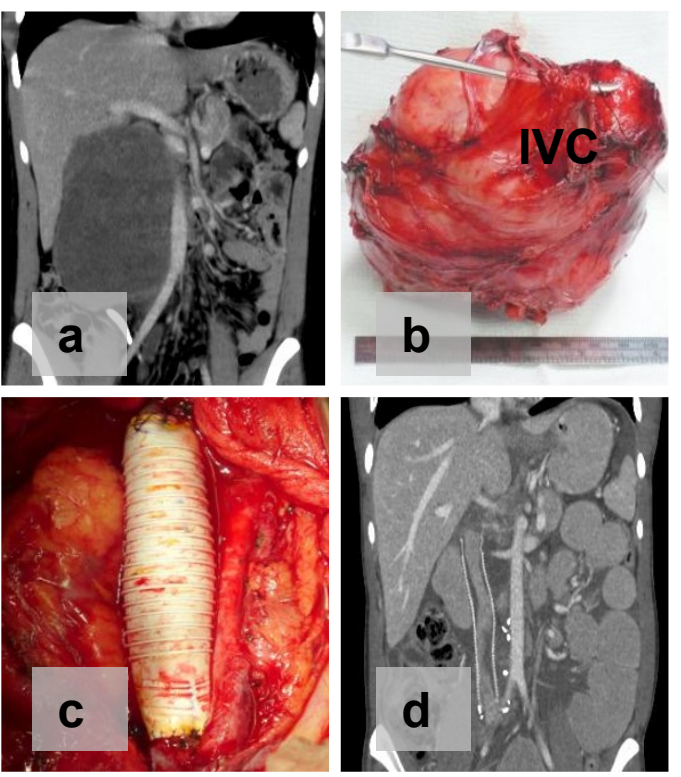

Figure 1 Retroperitoneal Tumor Involvement of the Inferior Vena Cava (IVC). Preoperative computed tomography scan demonstrates IVC involvement without obvious venous

collateralization (a). The tumor was resected en bloc with a portion of the IVC (b) and reconstructed using synthetic

polytetrafluoroethylene (PTFE) tube graft (c). Follow-up imaging was done postoperatively (d).

avoid iatrogenic injury to the ureter, ureteral stents were placed by urologists before laparotomy in 35\% of resections. Intraoperative femoral nerve monitoring, which we described previously [10], was done in $11 \%$ of cases to help identify the femoral nerve and prevent postoperative disability when involvement was suspected based on the location of the tumor and/or symptoms (e. g. paresthesias, pain, weakness).

With the exception of one patient with significant intraoperative bleeding (discussed below), all patients tolerated resection of their retroperitoneal tumor without intraoperative complications. A total of 24 complications were observed in the postoperative period. When

\section{Table 2 Complications}

\begin{tabular}{clc}
\hline $\begin{array}{l}\text { Revised Accordion Classification [ref [10]] } \\
\text { Grade }\end{array}$ & Type/Intervention Needed & $\begin{array}{c}\text { No. of } \\
\text { cases }\end{array}$ \\
\hline 1 & Minor procedures done at bedside & 2 \\
2 & Pharmacologic treatment, blood transfusions, & 12 \\
& TPN & 6 \\
3 & Endoscopic or interventional procedure & 3 \\
4 & General anesthesia, single organ failure & 0 \\
5 & Multi-organ (>2) organ failure & 1 \\
6 & Death & $\mathbf{2 4}$ \\
\hline & $\quad$ Total
\end{tabular}

scored according to the revised Accordion Classification scheme [11], the majority of complications were mild to moderate (Grade 1-3, Table 2). Major postoperative complications, as defined by organ failure, need for reoperation, or death (Grade 4-6), occurred in 16\% of cases. The most common complication overall was intra-abdominal abscess, which was managed by percutaneous drainage and parenteral antibiotics in all cases. The second most common complication was postoperative atrial fibrillation, which occurred in 4 patients. One patient had pre-existing atrial fibrillation, and none experienced a myocardial infarction. Atrial fibrillation was thought to be related to perioperative intravascular volume shifts and atrial stretch.

One patient had significant intraoperative bleeding that precluded complete resection and ultimately died (2\% 30-day series mortality). This patient had a primary epithelioid tumor with invasion into the vagina and rectum that required partial vaginectomy and abdominoperineal resection. Tumor dissection close to the sacrum led to profuse venous bleeding and massive blood transfusion requirements that necessitated damage control measures and cessation of surgery. The patient developed multi-organ failure and died on postoperative day four.

In total, median length of hospital stay for all patients was 7 days (range 4-72). 38\% (24/63) required postoperative recovery in the intensive care unit and among those patients, median length of stay was 4 days (range 1-23).

The final pathology results of resected retroperitoneal tumors revealed that $69 \%$ of cases had malignant disease. Among the malignant tumors, retroperitoneal sarcoma was the most common diagnosis $(72 \%, \mathrm{n}=32$ / 44). Liposarcoma was the most common sarcoma subtype $(55 \% ; \mathrm{n}=24 / 44)$, followed by leiomyosarcoma $(18 \% ; \mathrm{n}=8 / 44)$ (Figure 2a). Rare diagnoses such as undifferentiated pleomorphic sarcomas and spindle cell sarcomas were also seen. Among the benign tumors, schwannomas and paragangliomas were the most frequent (Figure 2b). Tumor sizes ranged from 2 to $48 \mathrm{~cm}$, with a median of $14 \mathrm{~cm}$. Only four tumors (7\%) were less than $5 \mathrm{~cm}$.

\section{Discussion}

Retroperitoneal tumors can be very challenging to manage. Large, single institution case series of retroperitoneal tumors suggest that most are malignant [1,2]. For malignant disease (i.e., sarcomas), completeness of resection is a critical prognostic factor for survival $[3,4,6]$. In fact, a recently proposed revised staging system and a survival nomogram both incorporate completeness of resection [12,13]. However, because retroperitoneal tumors are often enormous and close to critical 

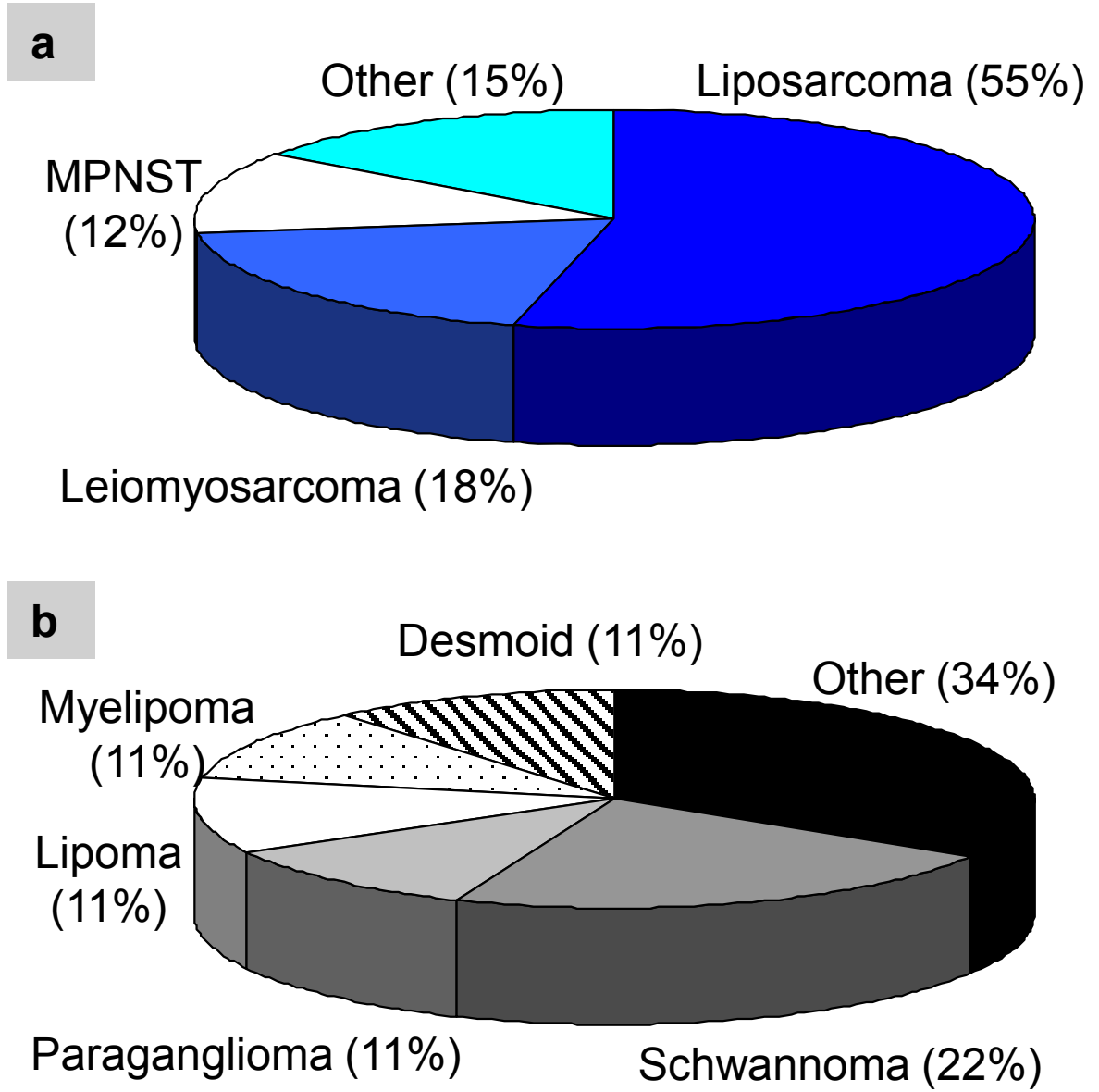

Figure 2 Final Pathology of Retroperitoneal Tumors. Among malignant tumors (a), sarcoma was the most common diagnosis. A variety of pathology was encountered for benign tumors (b). MPNST = malignant peripheral nerve sheath tumor.

retroperitoneal structures and organs, complete resection is difficult and the potential for perioperative complications is high. The results of our study suggest that for most patients, complete and safe resection is possible, but multi-organ and major vascular resections are frequently required and several adjunct procedures may be utilized to minimize complications.

For retroperitoneal tumors, large case series indicate that multi-organ resection is to be anticipated in up to $80 \%$ of patients, with the kidney being the most common organ resected en bloc with the primary tumor $[3,4,6]$. Although preoperative imaging studies may suggest adjacent organ involvement, often, definitive assessment can only be made intraoperatively. This underscores the importance of preoperative planning, especially if the visceral organs to be resected are outside of the surgeon's area of technical expertise. Assistance from consulting services may be needed.

Recently, Bonvalot et al. have advocated "complete compartmental surgery", which involves multi-organ resection, even without obvious tumor involvement of adjacent organs at the time of surgical exploration [14]. In a retrospective review of 382 patients undergoing retroperitoneal sarcoma resection, the authors found that this technique was associated with a 3-fold decrease in local recurrence in comparison to standard multi-organ resection only for tumor involvement. However, no difference in survival was noted. Santos et al. found that the technique of compartmental surgery did not appear to impact either recurrence rates or survival and was in fact, associated with higher intraoperative blood transfusion requirements and postoperative morbidity [15]. We did not utilize complete compartmental surgery in our series and believe that more studies are needed to validate its routine use.

Retroperitoneal tumors can also involve major abdominal vascular structures in up to $18 \%$ of patients [16], necessitating concomitant en bloc resection, as was done in five $(8 \%)$ of our cases. Preoperative planning is critical and should include consultation with a vascular surgeon for resection and reconstruction. For rightsided tumors, the surgeon must be prepared to resect 
the inferior vena cava (IVC) when a solid mass abuts it. Most published reports in patients with non-hepatic, non-renal primary retroperitoneal tumors advocate use of synthetic graft (e.g. polytetrafluoroethylene, PTFE) to reconstruct the IVC [16-19]. Graft patency rates are very good (90-94\%), as shown by studies with 19 to 36 months of follow-up review [16-19]. Alternatively, proximal ligation of the IVC after resection may be appropriate in select patients whose infrarenal tumors have extensive venous collateralization, or when concern for bowel anastomotic leakage would make synthetic graft placement risky. Minimal morbidity was reported in 11 patients who had proximal IVC ligation [20], but a subsequent report found that postoperative leg edema was twice as common after IVC ligation than after graft reconstruction [21]. Finally, although more rare and arguably more challenging, aortic resection for retroperitoneal tumors has also been described $[16,22,23]$. A variety of graft materials have been used for aortic resection, including Dacron [16], PTFE [16,22], polyethylene terephthalate [22], and even autologous superficial femoral vein [23]. Five patients with aortic resection and prosthetic reconstruction were reported to have a patency rate of $89 \%$ at 19 months [16]. For both venous and arterial reconstruction, the option of using cryopreserved human vein or extra-anatomic bypass (i.e. axillary-femoral) also exist, particularly when there is concern for enteric contamination within the resection site. In select cases, extracorporeal circulatory bypass may be helpful to permit complete and safe resection of retroperitoneal tumors with major vascular involvement [24].

In our series, complete resection was feasible for recurrent retroperitoneal tumors, although it was achieved slightly less often than for primary tumors (93\% versus $97 \%$, Table 1). Even more dramatic differences were reported by Lewis et al. more than a decade ago - $80 \%$ of patients with primary disease had complete resection versus $57 \%$ for those with local recurrence, and not surprisingly, the rate of complete resection continued to decrease with each subsequent recurrence [3]. Similar to our findings, more recent studies indicate a difference in the rate of complete resection, but suggest that the difference may not be as dramatic (99\% versus 90\%) [9]. The recent higher rates of complete resection for recurrent disease may reflect improved surgical technique, a more aggressive approach to resection of all retroperitoneal tumors, or improved patient selection. Complete resection should always be considered for recurrent disease as it is critical for improved survival [25] and in fact, may even result in comparable survival to patients after complete resection of primary disease [26].

Careful review of preoperative imaging is essential to anticipate potential operative scenarios and determine whether to utilize adjunct procedures to minimize complications. For example, ureteral stent placement and femoral nerve monitoring should be considered to identify these important structures when masses are near to their expected location in the retroperitoneum. Posterior laminotomy should be considered to permit complete resection of retroperitoneal tumors involving spinal nerve roots and when masses abut the vertebral bodies. Preoperative angioembolization of highly vascular tumors should be considered to minimize intraoperative blood loss.

Despite use of adjunct procedures, perioperative complications are common given the magnitude of the operations often required in retroperitoneal tumor resection. In terms of perioperative mortality, our $2 \%$ rate compares favorably to the $1-3 \%$ rates reported for large single institution patient cohorts $[3,6]$ and a recent ACS-NSQIP national database review [27]. Our complication rate of $16 \%$ is also comparable to the recent $13-$ $26 \%$ rates reported in the literature [6,27]. The caveat of reporting complications, of course, is that they are heavily dependent on the experience and expertise of the surgeon(s) and the resources of the institution, and are to some extent, driven by extent of the operation, which may differ from one patient to another.

Although not performed in our current series, laparoscopic resection of retroperitoneal tumors is emerging as a potential surgical option in select cases. Two recent series have suggested that in benign tumors without adjacent organ or vessel involvement, this approach can be done safely and result in good perioperative outcomes $[28,29]$. Tumor size does not appear to significantly affect blood loss or operative time, although the majority of tumors are relatively small $(<10 \mathrm{~cm})$. Laparoscopic resection of retroperitoneal liposarcoma $[30,31]$ and leiomyosarcoma [32,33] have also been described in case reports. We feel that use of this approach in malignant disease should be tempered by the same oncologic principles of complete and safe resection and that there should be a low threshold for conversion to laparotomy in cases of actual or potential adjacent organ involvement.

\section{Conclusion}

Our recent series of sixty-three cases of challenging primary and recurrent retroperitoneal tumor resections indicates that complete resection is feasible and can be done safely. The surgeon must take several factors into consideration, including the possibility of multi-organ and major vascular resection and the need for adjunct procedures to minimize complications. We fully advocate thorough preoperative planning and full utilization of institutional resources and consulting services on an individual patient basis. 


\section{Acknowledgements}

None

\section{Author details}

${ }^{1}$ Divisions of Surgical Oncology, University of California at San Francisco (UCSF), 505 Parnassus Avenue, San Francisco, CA 94143 USA. ${ }^{2}$ Vascular Surgery, Department of Surgery, University of California at San Francisco (UCSF), 505 Parnassus Avenue, San Francisco, CA 94143 USA. ${ }^{3}$ Current address: Department of Surgical Oncology, University of Texas MD Anderson Cancer Center, 1515 Holcombe Blvd, Houston, Texas 77030 USA.

\section{Authors' contributions}

WWT participated in the design of the study, carried out the extraction and analysis of data, wrote the manuscript, and performed critical review of the literature. SCW, CME and RSW assisted in collection of the clinical data and assisted in reviewing the manuscript. EKN conceived of and participated in the design of the study, assisted in collection of clinical data, and assisted in reviewing the manuscript. All authors have read and approved the final manuscript.

\section{Competing interests}

The authors declare that they have no competing interests.

Received: 18 July 2011 Accepted: 4 November 2011

Published: 4 November 2011

\section{References}

1. Xu YH, Guo KJ, Guo RX, Ge CL, Tian YL, He SG: Surgical management of 143 patients with adult primary retroperitoneal tumor. World $J$ Gastroenterol 2007, 13:2619-2621.

2. An JY, Heo JS, Noh JH, Sohn TS, Nam SJ, Choi SH, Joh JW, Kim SJ: Primary malignant retroperitoneal tumors: analysis of a single institutional experience. Eur I Surg Oncol 2007, 33:376-382.

3. Lewis JJ, Leung D, Woodruff JM, Brennan MF: Retroperitoneal soft-tissue sarcoma: analysis of 500 patients treated and followed at a single institution. Ann Surg 1998, 228:355-365.

4. Hueman MT, Herman JM, Ahuja N: Management of retroperitoneal sarcomas. Surg Clin North Am 2008, 88:583-597.

5. Nathan H, Raut CP, Thornton K, Herman JM, Ahuja N, Schulick RD, Choti MA, Pawlik TM: Predictors of survival after resection of retroperitoneal sarcoma: a population-based analysis and critical appraisal of the AJCC staging system. Ann Surg 2009, 250:970-976.

6. Strauss DC, Hayes AJ, Thway K, Moskovic EC, Fisher C, Thomas JM: Surgical management of primary retroperitoneal sarcoma. Br J Surg 2010, 97:698-706.

7. Gholami S, Jacobs CD, Kapp DS, Parast LM, Norton JA: The value of surgery for retroperitoneal sarcoma. Sarcoma 2009, 605840, Epub 2009 Oct 8 .

8. Erzen D, Sencar M, Novak J: Retroperitoneal sarcoma: 25 years of experience with aggressive surgical treatment at the Institute of Oncology, Ljubljana. J Surg Oncol 2005, 91:1-9.

9. Ferrario T, Karakousis CP: Retroperitoneal sarcomas: grade and survival. Arch Surg 2003, 138:248-251.

10. Guo L, Clark JP, Warren RS, Nakakura EK: Compound muscle action potentials and spontaneous electromyography can be used to identify and protect the femoral nerve during resection of large retroperitoneal tumors. Ann Surg Oncol 2008, 15:1594-1599.

11. Porembka MR, Hall BL, Hirbe M, Strasberg SM: Quantitative weighting of postoperative complications based on the accordion severity grading system: demonstration of potential impact using the american college of surgeons national surgical quality improvement program. J Am Coll Surg 2010, 210:286-298.

12. van Dalen T, Hennipman A, Van Coevorden F, Hoekstra HJ, van Geel BN, Slootweg P, Lutter CF, Brennan MF, Singer S: Evaluation of a clinically applicable post-surgical classification system for primary retroperitoneal soft-tissue sarcoma. Ann Surg Oncol 2004, 11:483-490.

13. Anaya DA, Lahat G, Wang X, Xiao L, Pisters PW, Cormier JN, Hunt KK, Feig BW, Lev DC, Pollock RE: Postoperative nomogram for survival of patients with retroperitoneal sarcoma treated with curative intent. Ann Oncol 2010, 21:397-402.
14. Bonvalot S, Rivoire M, Castaing M, Stoeckle E, Le Cesne A, Blay JY Laplanche A: Primary retroperitoneal sarcomas: a multivariate analysis of surgical factors associated with local control. J Clin Oncol 2009, 27:31-37.

15. Santos CE, Correia MM, Thuler LC, Rosa BR, Accetta A, de Almeida Dias J, de Mello EL: Compartment surgery in treatment strategies for retroperitoneal sarcomas: a single-center experience. World J Surg 2010, 34:2773-2781.

16. Schwarzbach MH, Hormann $Y$, Hinz U, Leowardi C, Böckler $D$, Mechtersheimer G, Friess H, Büchler MW, Allenberg JR: Clinical results of surgery for retroperitoneal sarcoma with major blood vessel involvement. J Vasc Surg 2006, 44:46-55.

17. Bower TC, Nagorney DM, Cherry KJ Jr, Toomey BJ, Hallett JW, Panneton JM, Gloviczki P: Replacement of the inferior vena cava for malignancy: an update. J Vasc Surg 2000, 31:270-281.

18. Sarkar R, Eilber FR, Gelabert HA, Quinones-Baldrich WJ: Prosthetic replacement of the inferior vena cava for malignancy. J Vasc Surg 1998, 28:75-81.

19. Kieffer E, Alaoui M, Piette JC, Cacoub P, Chiche L: Leiomyosarcoma of the inferior vena cava: experience in 22 cases. Ann Surg 2006, 244:289-295.

20. Hollenbeck ST, Grobmyer SR, Kent KC, Brennan MF: Surgical treatment and outcomes of patients with primary inferior vena cava leiomyosarcoma. J Am Coll Surg 2003, 197:575-579.

21. Cho SW, Marsh JW, Geller DA, Holtzman M, Zeh H, Bartlett DL, Gamblin TC: Surgical management of leiomyosarcoma of the inferior vena cava. $J$ Gastrointest Surg 2008, 12:2141-2148.

22. Song TK, Harris EJ Jr, Raghavan S, Norton JA: Major blood vessel reconstruction during sarcoma surgery. Arch Surg 2009, 144:817-822

23. McKay A, Motamedi M, Temple W, Mack L, Moore R: Vascular reconstruction with the superficial femoral vein following major oncologic resection. J Surg Oncol 2007, 96:151-159.

24. Miraziz R, Hines L, Brouwer M, Steel R, Klineberg P: Bridging circuit for the resection of retroperitoneal sarcoma involving the aorta and the IVC veno-venous to veno-arterial perfusion. Perfusion 2008, 23:65-69.

25. Grobmyer SR, Wilson JP, Apel B, Knapik J, Bell WC, Kim T, Bland KI, Copeland EM, Hochwald SN, Heslin MJ: Recurrent retroperitoneal sarcoma: impact of biology and therapy on outcomes. J Am Coll Surg 2010, 210:602-608.

26. Sogaard AS, Laurberg JM, Sorensen M, Sogaard OS, Wara P, Rasmussen $P$, Laurberg S: Intraabdominal and retroperitoneal soft-tissue sarcomasoutcome of surgical treatment in primary and recurrent tumors. World J Surg Oncol 2010, 8:81-85.

27. Tseng WH, Martinez SR, Tamurian RM, Chen SL, Bold RJ, Canter RJ: Contiguous organ resection is safe in patients with retroperitoneal sarcoma: An ACS-NSQIP analysis. J Surg Oncol 2011, 103:390-394.

28. Zhang Z, Xiu D: Laparoscopic surgery for primary retroperitoneal tumors: a single institution experience of 14 cases. Surg Laparosc Endosc Percutan Tech 2010, 20:399-403.

29. Ahn KS, Han HS, Yoon YS, Kim HH, Lee TS, Kang SB, Cho JY: Laparoscopic resection of nonadrenal retroperitoneal tumors. Arch Surg 2011, 146:162-167.

30. Ball AJ, Siddiq FM, Garcia M, Ganjei-Azar P, Leveillee RJ: Hand-assisted laparoscopic removal of retroperitoneal liposarcoma. Urology 2005, 65:1226 e9-e11.

31. Dalpiaz O, Gidaro S, Lipsky K, Schips L: Case report: Laparoscopic removal of 10-cm retroperitoneal liposarcoma. J Endourol 2007, 21:83-84.

32. Viani MP, Poggi RV, Pinto A, Maruotti RA: Gasless laparoscopic removal of retroperitoneal leiomyosarcoma. J Laparoendosc Surg 1995, 5:47-54.

33. Agresta F, De Simone P, Michelet I, Bedin N: Retroperitoneal leiomyosarcoma mimicking acute appendicitis: laparoscopic management. JSLS 2003, 7:177-179.

doi:10.1186/1477-7819-9-143

Cite this article as: Tseng et al:: Complete and safe resection of challenging retroperitoneal tumors: anticipation of multi-organ and major vascular resection and use of adjunct procedures. World Journal of Surgical Oncology 2011 9:143. 